\title{
MAPAS DE FLUXOS E PERMANÊNCIAS: MÉTODO PARA ESTUDO DOS PERCURSOS DO CENTRO DE EDUCAÇÃO E CULTURA ANSELMO DUARTE - SALTO/SP.
}

\author{
BAPTISTA, Mariana Bertani (1); \\ BERNARDI, Núbia (2) \\ (1) Universidade Estadual de Campinas, Programa de Pós Graduação em \\ Arquitetura. Tecnologia e Cidade, Arquiteta e Urbanista \\ e-mail:marianabaptista.arquiteta@gmail.com \\ (2) Universidade Estadual de Campinas, Faculdade de Engenharia Civil, Arquitetura e \\ Urbanismo, Professora Doutora \\ e-mail:nubiab@fec.unicamp.br
}

\begin{abstract}
RESUMO
Notando a lacuna de estudos de percursos em ambientes internos com foco no Desenho Universal, este artigo resume a metodologia desenvolvida para uma pesquisa de mestrado. O objetivo foi propor uma ferramenta prática capaz de ser aplicada em ambientes internos e externos, que auxiliasse no processo criativo e na correção de ambientes construídos sem acessibilidade. Baseado na análise de elementos construtivos proposta por Unwin (2013), complementado por mapeamento de fluxos, e tabelas analíticas de parâmetros de acessibilidade e Desenho Universal, o método foi aplicado na Sala Palma de Ouro, no Centro de Educação e Cultura Anselmo Duarte, em Salto - SP.
\end{abstract}

Palavras-chave: Acessibilidade, Desenho Universal, Análise de Projetos.

\begin{abstract}
Noting the lack of studies of pathways in internal environments, and with a focus also on Universal Design, this paper resumes a method developed for a master's research. The objective was to come up with a tool capable of being applied in internal and external environments, helping creative process and correction of built environments without accessibility. Based on the analysis of constructive elements developed by Unwin (2013), complemented by mapping of flows and analytical tables of accessibility and Universal Design parameters, the method was applied at Sala Palma de Ouro, in Anselmo Duarte Education and Culture Center, in Salto - SP.
\end{abstract}

KEYWORDS: Acessibility, Universal Design, Project Analysis.

\section{INTRODUÇÃO}

A Declaração Universal dos Direitos do Homem, redigida em 1948, e que nasceu do propósito de salvar as gerações futuras da devastação do conflito internacional, atualmente funciona como um contrato entre um governo e o seu povo. O documento é composto por 30 artigos, no entanto neste trabalho nos compete destacar os artigos $1^{\circ}$ e $3^{\circ}$ que dizem, respectivamente: 


\section{$\dddot{R}^{\text {eneac }}$}

Todos os seres humanos nascem livres e iguais em dignidade e em direitos. Dotados de razão e de consciência, devem agir uns para com os outros em espírito de fraternidade. [...]

Todas as pessoas têm direito à vida, à liberdade e à segurança pessoal.

Aliado à Declaração dos Direitos Humanos, a Constituição da República Federativa do Brasil de 1988, em seu artigo 5ㅜ, item XV, garante a livre locomoção no território nacional em tempo de paz, podendo qualquer pessoa, nos termos da lei, nele entrar, permanecer, ou dele sair com seus bens. A partir deste texto, a acessibilidade a logradouros públicos se torna direito dos habitantes e dever do Estado, através dos seus artigos 227 e 244, que dizem:

Art. 227. Omissis. § $2^{\circ}$. A lei disporá sobre normas de construção de logradouros e dos edifícios de uso e de fabricação de veículos de transporte coletivo, a fim de garantir acesso adequado às pessoas portadoras de deficiência.

Art. 244. A lei disporá sobre a adaptação dos logradouros, dos edifícios de uso público e dos veículos de transporte coletivos atualmente existentes a fim de garantir acesso adequado às pessoas portadoras de deficiência, conforme disposto no art. 227, $2^{\circ}$.

Tal concretização do direito de ir e vir é fundamental para as pessoas com deficiência, pois as habilitam a usufruir dos demais direitos universais: Trabalho, Lazer, Estudo, etc. (FElJÓ, 2002). Aguiar et al (2008) apontam que por esta razão a mobilidade tem sido uma das maiores preocupações do Poder Público, através do Ministério das Cidades, que tem priorizado a mobilidade dos pedestres a partir dos princípios do Desenho Universal. Afirmam também que de modo geral, estas ações ainda se limitam a readequações dos espaços sem o conhecimento aprofundado das características físicas de locomoção das pessoas com mobilidade reduzida, cadeirantes, surdos e cegos. É comum que a construção de rampas nas esquinas das calçadas seja considerada "suficiente" para classificar o projeto urbano como inclusivo (DUARTE e COHEN, 2004).

A partir dos pressupostos de prover a equiparação do uso, a flexibilidade simples e intuitiva do uso, assegurar a percepção de informação minimizando os riscos de acidentes e oferecendo um espaço para uso e interação que exija pouco esforço físico, o Desenho Universal é a forma de conceber tais ambientes com qualidade. Para Story (2001) o objetivo do Desenho Universal é beneficiar simultaneamente todas as idades e capacidades, ou seja, o Desenho Universal deve providenciar um ambiente de integração, que estabeleça formas comuns de vida, de aprendizagem e de trabalho entre pessoas com e sem deficiência.

No Brasil, a primeira Norma Técnica cujo escopo específico foi a acessibilidade no ambiente construído, foi redigida em 1985, pelo Comitê Brasileiro de Construção Civil (CB-002) e intitulada NBR 9050 - Adequação das edificações, equipamentos e mobiliário urbano à pessoa portadora de deficiência. Em 1994 ocorre a primeira revisão da Norma por um comitê específico, o Comitê Brasileiro de Acessibilidade (CB-040), e a Norma passa a se denominar NBR 9050 - Acessibilidade de pessoas com deficiências a edificações, espaço, mobiliário e equipamentos urbanos. Procedimentos, e em 2004 é feita uma nova revisão oficial pelo CB-040, onde passa a se chamar NBR 9050 - Acessibilidade a edificações, mobiliário, espaços e equipamentos urbanos, que vigorou até outubro de 2015, quando passa a vigorar a nova versão da Norma, redigida a partir das consultas publicas de 2008 e 2012, e mantendo o mesmo nome.

No espaço de três décadas a Norma passou de um documento estritamente focado em pessoas com alguma deficiência, para em sua última versão (Norma NBR 9050/2015), um documento com preocupações mais universalizadas, atentando-se para as necessidades de mobilidade e comunicação de diferentes tipos de usuários: deficientes, idosos, gestantes, obesos, pessoas com crianças de colo ou carregando objetos, etc. Na versão atual as 


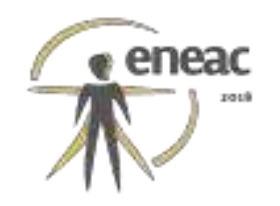

palavras-chave diminuíram em número, ficando apenas os termos: ergonomia, pessoa com mobilidade reduzida, cadeira de rodas, mobiliário, deficiente físico, pessoa portadora de deficiência física, piso antiderrapante e piso tátil. Essa seleção mais restrita em relação às versões anteriores demonstra um amadurecimento e uma melhor organização das ideias e parâmetros apresentados na atual Norma NBR 9050:2015.

Para avaliar a utilização do Desenho Universal (DU) e o cumprimento da Norma NBR 9050 em ambientes construídos, esta pesquisa aplicou uma metodologia de análise baseada nos princípios do DU e nos itens da Norma referentes a percursos e deslocamentos, traduzindo os resultados em Mapas de Fluxos e Permanências. Em arquitetura, o edifício institucional é o espaço público cujas características principais são a abrangência de usuários, a coletividade e uso social. Tem como finalidade receber um grande e variado número de visitantes, comumente num fluxo de médio a grande e, em geral, são espaços construídos em locais de fácil acesso, com uma arquitetura que o torne perceptível no ambiente.

Nesta pesquisa foi proposto limitar a aplicação da ferramenta apenas ao percurso público existente internamente e externamente ao edifício institucional, e de preferência concebido no intervalo de revisão da NBR 9050 - de 2004 a 2015 - para validar a eficiência do método e da ferramenta. Como edifício objeto do estudo foi selecionado a Sala Palma de Ouro, no Centro de Educação e Cultura Anselmo Duarte, em Salto/SP. Trata-se de um projeto de 2006, com obra concluída em 2009, contendo uma Sala de Teatro com capacidade para 480 pessoas, toda a estrutura para o funcionamento da sala, além de departamentos e auditório de uso exclusivo da Secretaria de Educação Municipal. A ferramenta foi aplicada no entorno do Teatro e nos percursos internos para acesso a bilheteria, chapelaria, café e sanitários, foyer e sala de teatro - Sala Palma de Ouro.

\section{OBJETIVO}

O Objetivo Geral foi elaborar uma ferramenta prática de análise de fluxos e permanências da Acessibilidade e do Desenho Universal.

\section{JUSTIFIVATIVA}

No Brasil, a última década foi marcada por novos projetos arquitetônicos que necessariamente contemplaram a acessibilidade devido a diversos fatores, como a instituição dos Planos Diretores Participativos nas cidades, criação de leis de apoio à inclusão e da aparente universalização dos espaços devido aos eventos esportivos que ocorreram nos últimos anos. Neste mesmo intervalo de tempo (2004 a 2014) ocorreram as duas consultas públicas para a atualização da Norma NBR 9050, em 2008 e 2012.

Neste contexto se faz importante realizar um estudo de caso baseado na atualização da Norma e aplicado a um edifício que foi construído no intervalo entre as revisões, para mensurar a qualidade das soluções que estão sendo adotadas para o cumprimento da NBR 9050, bem como para detectar se estão sendo adotadas soluções compatíveis com os Sete Princípios do Desenho Universal.

\section{CONSTRUÇÃO DO MÉTODO}

A pesquisa teve três fases definidas como: Pesquisa, Estudo e Diagnóstico.

A fase de Pesquisa consistiu principalmente no levantamento de bibliografia referente aos temas estudados e documentos de projeto, incluindo material iconográfico. A fase de Estudo 


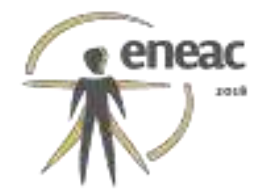

foi subdividida em duas etapas: a etapa inicial foi o estudo da documentação levantada, seguida pela etapa de visitas e medições do local, realizadas na Sala Palma de Ouro (Salto/SP).

A fase Diagnóstico onde foram empregados os métodos de análise, também foi subdividida em duas etapas de acordo com a metodologia empregada:

1) Metodologia baseada na análise de elementos construtivos de Unwin (2013) tem seu foco no ambiente físico, e a fase deste estudo coincidiu com a análise gráfica do projeto selecionado.

2) Mapa de Fluxo e Permanência: ferramenta que ilustra empiricamente o espaço e o tempo de permanência e de percurso dos indivíduos dentro do ambiente físico, e nesta pesquisa foi utilizada para orientar as observações feitas durante a análise no local. O Mapa de Fluxo e Permanência é uma adaptação da autora desta pesquisa sobre o mapa comportamental de Rheingantz et al (2009).

As duas metodologias utilizadas possuem o mesmo foco, utilizando ferramentas diferentes, porém complementares.

\subsection{Metodologia de Unwin}

Simon Unwin nasceu em 1952, na Inglaterra, estudou na Escola Galesa de Arquitetura de Cardiff, onde elaborou sua tese de doutoramento. Atualmente é professor emérito de Arquitetura da Universidade de Dundee, na Escócia. Sua obra de maior destaque é o livro intitulado „A análise da arquitetura', onde Unwin estrutura sua análise a partir dos elementos construídos da arquitetura. Seu discurso começa com a ideia do estabelecimento do lugar, buscando as raízes da necessidade do homem primitivo em definir um local para a realização das atividades inerentes à sua sobrevivência, como alimentar-se, descansar, proteger-se do clima, entre outras atividades.

Unwin (2013) classifica os elementos construtivos como:

- Elementos Básicos: área de terreno definida, área elevada ou plataforma, área rebaixada ou vala, marco, foco, barreira, percurso e aberturas;

- Elementos Combinados: barreiras que formam fechamentos. Fechamento com cobertura que formam uma cela, colunas e cobertura que formam uma edícula, fechamento e colunas que formam uma galeria, plataformas em ângulo que formam uma escada.

- Elementos Modificadores: luz, cor, temperatura, ventilação, som, odor, textura e tato, escala, e tempo

Unwin (2013) aponta que com o lugar estabelecido e definido pelos elementos da arquitetura percebe-se a necessidade de organizar os espaços de acordo com as atividades que se realizam, e isso se dá novamente pelo emprego de outros elementos, básicos ou modificadores, através de estratégias de organização que permitam o uso desejado o que resulta na maioria das vezes em elementos sendo utilizados com mais de uma função, denotando a qualidade do projeto em questão (Quadro 1). 


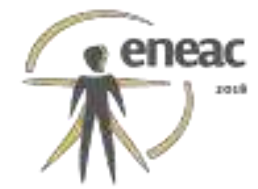

Quadro 1: As estratégias de organização do espaço propostos por Unwin.

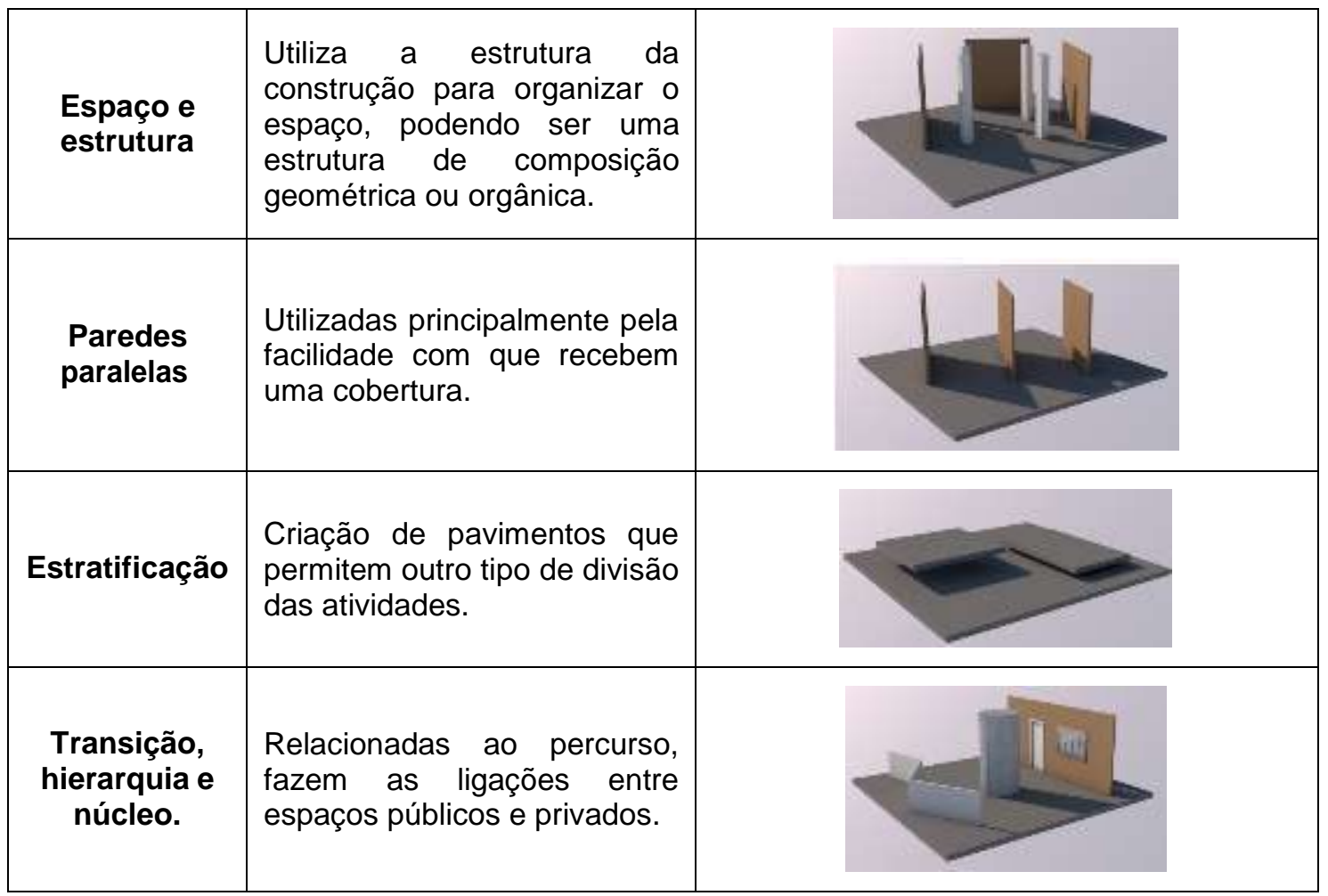

Fonte: Modificado de UNWIN (2013) pelas autoras, 2015.

A metodologia de análise proposta por Unwin foi utilizada para identificar os elementos de arquitetura responsáveis por criar ambientes de uso e acesso universais. Aplicada sobre o material iconográfico do Centro de Educação e Cultura Anselmo Duarte com o intuito de preparar o Roteiro da Visita e refinar o olhar para os pontos do projeto com aspectos relevantes do Desenho Universal.

\subsection{Mapa de Fluxo e Permanência}

A análise no local em uso resultou em Mapas de Fluxo e Permanência dos usuários. Este material auxiliou a verificação da congruência do ambiente projetado ao efetivamente existente, tornando-se imprescindível para validar a análise dos documentos iconográficos feitas no início da pesquisa. Apesar de ter o lugar como objeto de análise, os estudos de Fluxo e Permanência estão intimamente ligados aos usuários, pois é através das condutas dos indivíduos que são identificados parte dos atributos do ambiente.

Os fluxos e permanências foram estudados com o auxilio das plantas dos locais, e os usuários foram divididos em três tipos, de acordo com a atividade que desenvolveriam no local:

- Transeuntes: para os que utilizaram os espaços apenas para locomoção de uma rua à outra;

- Expectadores: para os que utilizaram o espaço para acessar Centro de Educação e Cultura Anselmo Duarte e assistir a um espetáculo; 


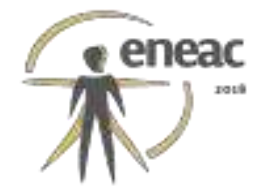

- Participantes de outras atividades: para os que utilizaram o local para desenvolver outras atividades - participar de workshops, feiras e eventos realizados na área externa ou nos camarins.

Cada tipo de usuário recebeu uma cor diferente para distinguir com clareza as necessidades de percurso de cada grupo. (Figura 1).

\section{Figura 1: Exemplo de Mapa de Fluxo e Permanência utilizado nesta pesquisa}

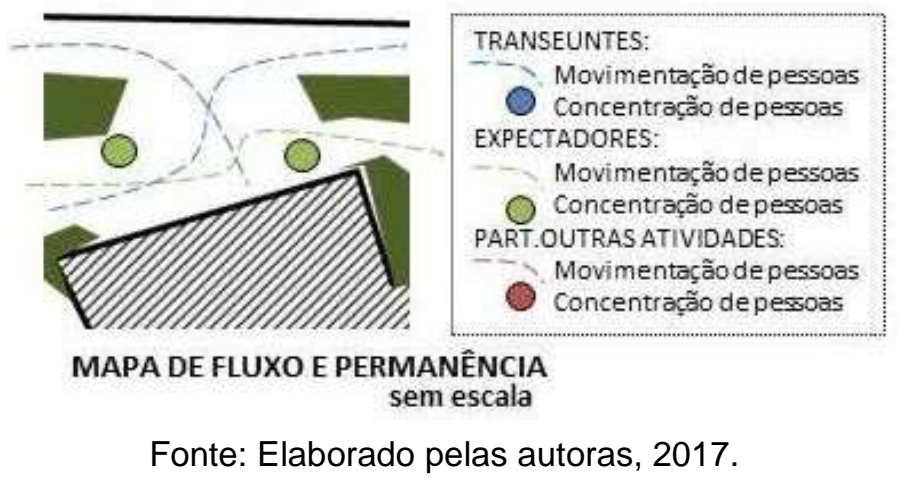

\subsection{Tabelas Analíticas}

Para organizar e facilitar a análise Centro de Educação e Cultura Anselmo Duarte e seu entorno de acordo com os parâmetros da Norma NBR 9050/2015 e dos Sete Princípios do Desenho Universal, foram confeccionadas Tabelas Analíticas com os itens a serem observados e uma escala de atendimento, para que fossem levantadas também as possibilidades de melhorias em termos de acessibilidade e Desenho Universal.

O critério de análise foi baseado no atendimento, de acordo com a seguinte escala em ordem crescente: "não há atendimento" - quando o parâmetro observado não foi identificado no local, "Atendimento mínimo" - quando o parâmetro foi observado de modo muito superficial ou sem o cuidado necessário; "Atendimento parcial, passível de melhoria" quando o parâmetro foi identificado, porém existe a possibilidade de ser melhorado;

"Atendimento parcial sem possibilidade de melhoria" - quando o parâmetro foi identificado, necessitando melhoria, mas sem a possibilidade de executar essa melhoria sem influenciar em outras estruturas (edificações e sistemas viários); „Atendimento total' - quando o parâmetro é atendido de forma completa, servindo como exemplo de aplicação de acessibilidade e/ou Desenho Universal.

As tabelas foram aplicadas separadamente a cada trecho do objeto de estudo. A setorização dos ambientes para aplicação das tabelas analíticas foi baseada nos elementos propostos por Unwin (2013) e no uso de cada ambiente, separados por fluxo e tipo de usuário - transeuntes, que só utilizam a quadra para locomoção; expectadores - que utilizam os locais para chegar até a plateia; e participantes de outras atividades - que se dirigem ao local para participar de atividades diversas às de assistir espetáculos, como oficinas de dança e atuação, ensaios musicais e atividades escolares.

Para a construção das tabelas analíticas utilizou-se como parâmetro os itens da Norma NBR 9050 referentes a percursos e espaços de breve permanência, e os Sete Princípios do Desenho Universal. As duas tabelas foram aplicadas em todos os ambientes estudados, possibilitando o levantamento de informações especificas de cada ambiente. As Figuras 2 e 3 mostram trechos destas tabelas. 


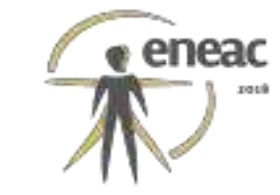

Figura 2 - Trecho da Tabela Analítica para acessibilidade destacando os Parâmetros da Norma NBR 9050/2015 - tabela utilizada para avaliar o trecho da chapelaria.

\begin{tabular}{|c|c|c|c|c|c|c|c|c|}
\hline \multirow{2}{*}{$\begin{array}{c}\text { ITEM } \\
\text { DA } \\
\text { NBR } \\
9050 \\
/ 201 \\
5\end{array}$} & \multirow{2}{*}{$\begin{array}{c}\text { SUB } \\
\text { ITEM } \\
\text { DA } \\
\text { NBR } \\
9050 / \\
2015\end{array}$} & \multirow{2}{*}{$\begin{array}{c}\text { ATENDIME } \\
\text { NTO } \\
\text { PREVISTO } \\
\text { NA NBR } \\
9050\end{array}$} & \multicolumn{5}{|c|}{ ATENDIMENTO REAL } & \multirow{4}{*}{$\begin{array}{c}\text { RESUL } \\
\text { TADO: } \\
\text { Falta } \\
\text { balcão } \\
\text { de } \\
\text { atendim } \\
\text { ento } \\
\text { para } \\
\text { cadeiran } \\
\text { te e } \\
\text { identific } \\
\text { ação } \\
\text { tátil. }\end{array}$} \\
\hline & & & $\begin{array}{l}\text { Não } \\
\text { há } \\
\text { atendi } \\
\text { mento }\end{array}$ & $\begin{array}{c}\text { Atendi } \\
\text { mento } \\
\text { mínim } \\
0\end{array}$ & $\begin{array}{c}\text { Atendimen } \\
\text { to parcial, } \\
\text { passivel } \\
\text { de } \\
\text { melhora. }\end{array}$ & $\begin{array}{l}\text { Atendiment } \\
\text { o parcial } \\
\text { sem } \\
\text { possibilidad } \\
\text { e de } \\
\text { melhora. }\end{array}$ & $\begin{array}{c}\text { Atendi } \\
\text { mento } \\
\text { total. }\end{array}$ & \\
\hline \multirow{5}{*}{$\begin{array}{l}4.3 \\
\text { Area } \\
\text { de } \\
\text { circul } \\
\text { ação } \\
\text { e } \\
\text { man } \\
\text { obra }\end{array}$} & \multirow{5}{*}{$\begin{array}{l}4.3 .3 \\
\text { Mobiliá } \\
\text { rios na } \\
\text { rota } \\
\text { acessí } \\
\text { vel }\end{array}$} & $\begin{array}{l}\text { Não há } \\
\text { mobiliário. }\end{array}$ & & & $\begin{array}{l}\text { Não se } \\
\text { aplica }\end{array}$ & & & \\
\hline & & $\begin{array}{l}\text { Mobiliário } \\
\text { não } \\
\text { necessita } \\
\text { proteção - } \\
\text { possui } \\
\text { menos de } \\
10 \mathrm{~cm} \text { de } \\
\text { saliência. }\end{array}$ & & & & & $x$ & \\
\hline & & $\begin{array}{l}\text { Mobiliário } \\
\text { apresenta } \\
\text { contraste } \\
\text { visual } \\
\text { mínimo. }\end{array}$ & & & & & $x$ & \\
\hline & & $\begin{array}{l}\text { Mobiliário } \\
\text { apresenta } \\
\text { sinalização } \\
\text { tátil e visual } \\
\text { de alerta. }\end{array}$ & $x$ & & & & & \\
\hline & & $\begin{array}{l}\text { Mobiliário } \\
\text { possui } \\
\text { proteção } \\
\text { lateral } \\
\text { instalada a } \\
\text { menos de } \\
60 \mathrm{~cm} \text { do } \\
\text { piso. }\end{array}$ & & & $\begin{array}{l}\text { Não } \\
\text { aplica }\end{array}$ & & & \\
\hline
\end{tabular}

Fonte: Elaborado pelas autoras, 2017. 


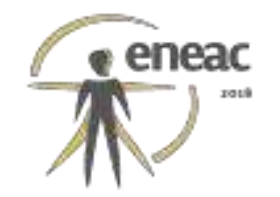

Figura 3 - Tabela Analítica para Desenho Universal - Sete Princípios - tabela utilizada para avaliar o trecho da chapelaria.

\begin{tabular}{|c|c|c|c|c|c|c|c|}
\hline \multirow[b]{2}{*}{$\begin{array}{c}\text { SETOR } \\
\text { AMBIE } \\
\text { NTE }\end{array}$} & \multirow[b]{2}{*}{$\begin{array}{c}\text { PRINCIPIO } \\
\text { S DO } \\
\text { DESENHO } \\
\text { UNIVERSA } \\
\text { L }\end{array}$} & \multicolumn{5}{|c|}{ ATENDIMENTO REAL } & \multirow[b]{2}{*}{$\begin{array}{l}\text { RESUL } \\
\text { TADO: }\end{array}$} \\
\hline & & $\begin{array}{l}\text { N ão há } \\
\text { atendim } \\
\text { ento }\end{array}$ & $\begin{array}{l}\text { Atendime } \\
\text { nto } \\
\text { mínimo }\end{array}$ & $\begin{array}{c}\text { tendimen } \\
\text { b parcial, } \\
\text { passível } \\
\text { de } \\
\text { melhora. }\end{array}$ & $\begin{array}{l}\text { Atendiment } \\
\text { o parcial } \\
\text { sem } \\
\text { possibilidad } \\
\text { e de } \\
\text { melhora }\end{array}$ & $\begin{array}{l}\text { Atendi } \\
\text { mento } \\
\text { total. }\end{array}$ & \\
\hline \multirow{7}{*}{$\begin{array}{l}\text { Chapela } \\
\text { ria - } \\
\text { acesso } \\
\text { do } \\
\text { usuário. }\end{array}$} & $\begin{array}{l}\text { 1.Utilização } \\
\text { equitativa }\end{array}$ & $x$ & & & & & \multirow{7}{*}{$\begin{array}{l}\text { Existe } \\
\text { um } \\
\text { segrega } \\
\text { ção } \\
\text { imposta } \\
\text { principal } \\
\text { mente } \\
\text { pelo } \\
\text { balcão } \\
\text { de } \\
\text { atendim } \\
\text { ento } \\
\text { alto. } \\
\text { Sugestõ } \\
\text { es: } \\
\text { rebaixar } \\
\text { o } \\
\text { balcão, } \\
\text { sinalizar } \\
\text { o piso } \\
\text { estudar } \\
\text { a } \\
\text { possibili } \\
\text { dade de } \\
\text { destaca } \\
\text { um } \\
\text { mapa } \\
\text { tátil. }\end{array}$} \\
\hline & $\begin{array}{l}\text { 2.Flexibilida } \\
\text { de de } \\
\text { utilização - } \\
\text { adaptável; }\end{array}$ & $x$ & & & & & \\
\hline & $\begin{array}{l}\text { 3.Utilização } \\
\text { simples e } \\
\text { intuitiva; }\end{array}$ & & & & & $x$ & \\
\hline & $\begin{array}{l}4 . \\
\text { Informação } \\
\text { perceptível; }\end{array}$ & & & $x$ & & & \\
\hline & $\begin{array}{l}\text { 5.Toleranci } \\
\text { a ao erro; }\end{array}$ & & & $x$ & & & \\
\hline & $\begin{array}{l}\text { 6.Esforço } \\
\text { físico } \\
\text { mínimo; }\end{array}$ & & & & & $x$ & \\
\hline & $\begin{array}{l}7 . \\
\text { Dimensão } \\
\text { e espaço } \\
\text { de } \\
\text { utilização. }\end{array}$ & & & & & $x$ & \\
\hline
\end{tabular}

Fonte: Elaborado pelas autoras, 2017.

\section{A METODOLOGIA NA PRÁTICA}

\section{1 - Identificando os Espaços através da Classificação de Elementos de Unwin (2013):}

A análise do edifício quanto a acessibilidade e Desenho Universal foi realizada em duas etapas. A primeira etapa identificou os espaços dentro da análise da materialidade dos espaços construídos propostos por Unwin (2013). Em seguida, a segunda etapa, consistiu na definição dos espaços da Centro de Educação e Cultura Anselmo Duarte a serem estudados, tanto internos como externos, onde foram aplicadas as Tabelas Analíticas e desenhado o Mapa de Fluxo e Permanência. 


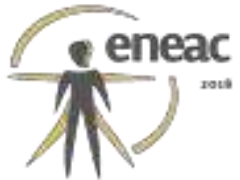

A aplicação do método de Unwin (2013) gerou as seguintes classificações, onde apenas as duas primeiras estão ilustradas com fotos.

\subsection{1 - Área Elevada:}

O palco da Sala Palma de Ouro, dentro do Centro de Educação e Cultura Anselmo Duarte, é caracterizado como área elevada por estar cerca de um metro acima do pavimento mais baixo pertencente á plateia (Figura 4).

\subsection{2 - Área Rebaixada:}

O acesso ao foyer e plateia da Sala Palma de Ouro se dá através de uma área rebaixada em face da rua de acesso ao edifício, respeitando o declive natural do terreno (Figura 5).

Figuras 4 e 5 - AREA ELEVADA - Diferença de nível entre palco e plateia. AREA REBAIXADA Diferença de nível entre a Rua Prudente de Moraes e a entrada da Sala Palma de Ouro.

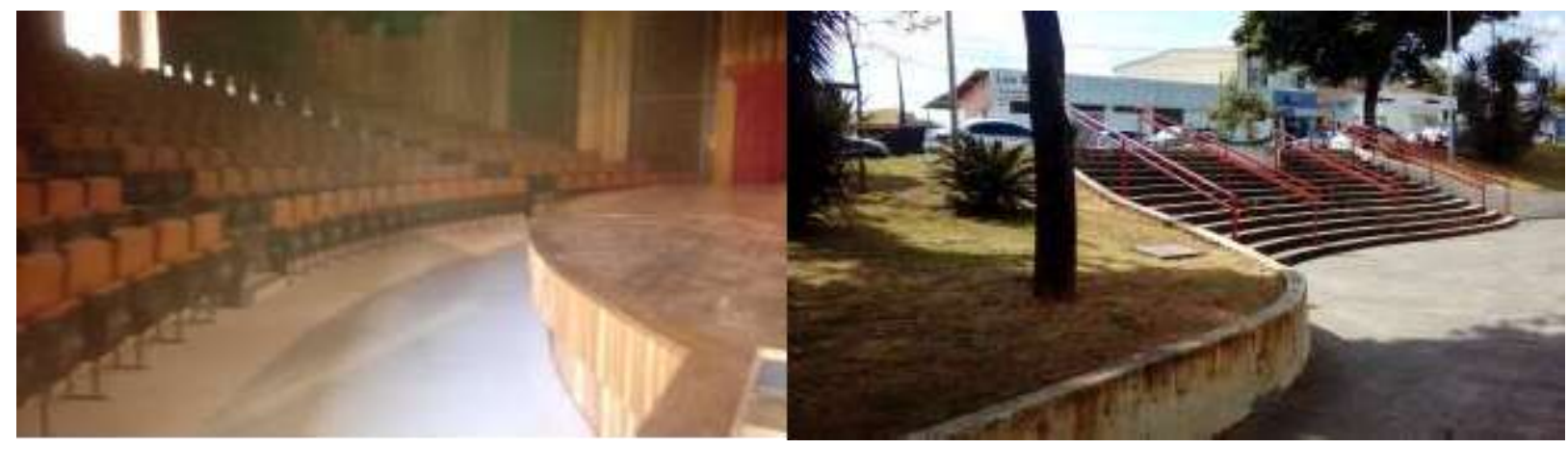

Fotos: Mariana Baptista, 2017.

\subsection{3 - Marco:}

A volumetria externa do edifício funciona como um Marco em todas as suas fachadas, mas principalmente na fachada de frente e de fundos, onde grandes colunas e vigas, setorizam a fachada enquanto sustentam a cobertura da caixa cênica da Sala Palma de Ouro.

\subsection{4 - Barreira:}

A topografia do terreno é a barreira que mais se destaca por conta de seus desníveis naturais. No projeto essa barreira foi resolvida externamente com a implantação de passeios em rampas suaves, e internamente criou-se uma barreira entre os espaços públicos e semipúblicos através de aberturas e fechamentos.

\subsection{5 - Foco:}

Externamente, o edifício apresenta como ponto focal a passarela que dá acesso à Secretaria de Educação. Internamente, o ponto focal é um painel de madeira onde está afixado um elemento decorativo representando a Palma de Ouro. 


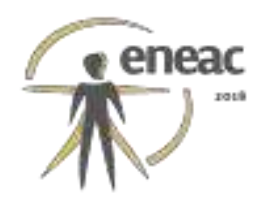

\subsection{6 - Percurso:}

Externamente o edifício é marcado por percurso em diferentes níveis, vencidos de forma harmônica com a utilização de escadas e rampas suaves. Internamente o percurso valoriza a Sala Palma de Ouro, colocando os outros percursos como secundários.

\subsection{7 - Aberturas:}

As aberturas são fechadas com panos envidraçados, mesclando o ambiente interno com os jardins externos. Por meio dessas aberturas os espaços se ampliam.

\subsection{8 - Luz:}

Toda a fachada foi tratada na cor branca, contrastando com os edifícios do entorno, e projetando sombras interessantes na própria fachada.

\subsection{9 - Escala:}

Externamente a escala da construção contrasta com o entorno e confere importância ao prédio. Internamente a construção volta-se à escala humana e oferece um espaço amplo sem ser agressivo.

\section{2 - Aplicação das Tabelas Analíticas e Desenho do Mapa de Fluxo e Permanência:}

As Tabelas Analíticas foram aplicadas em oito trechos externos e oito trechos internos Centro de Educação e Cultura Anselmo Duarte (CEC), de percurso público, setorizados de acordo com a classificação de elementos construtivos de Unwin (2013). Foram observados os atendimentos aos parâmetros da Norma NBR 9050/2015 e do Desenho Universal, classificando os trechos em mais acessíveis, ou menos acessíveis.

O Mapa de Fluxo e Permanência complementou a aplicação das tabelas analíticas ao incluir a utilização dos espaços pelos usuários e foi aplicado em duas situações diferentes: a) durante o dia, em horários em que não estivessem ocorrendo espetáculos ou outras atividades no Centro de Educação e Cultura Anselmo Duarte; b) durante o dia ou durante a noite, quando estivessem ocorrendo espetáculos ou outras atividades no CEC.

Apesar de ter sido aplicado nos mesmos locais onde foram aplicadas as Tabelas Analíticas, - Mapa de Fluxo e Permanência coletou informações relevantes apenas nos locais próximos à entrada da Sala Palma de Ouro. O Mapa de Fluxo e Permanência foi realizado com auxilio das plantas do CEC e entorno. (Figuras 6 e 7). Na Figura 6 podemos notar que os expectadores se concentram em uma das esquinas, a mais próxima da entrada do teatro, e os transeuntes se concentram, ou na esquina oposta ou no meio da quadra junto ao ponto de ônibus, e os fluxos de transeuntes se dão pelo limite com o leito da rua, e dos expectadores, pelo interior da quadra. Já a Figura 7 mostra a movimentação dos expectadores e seus pontos de concentração no foyer da Sala Palma de Ouro.

O método foi aplicado em oito trechos externos - calçadas, praças internas e estacionamento - e em oito trechos internos - bilheteria, foyer, chapelaria, café, acesso aos sanitários, exposições, plateia e palco. 


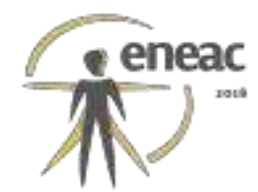

Figuras 6 e 7 - Acima: Planta utilizada para o Mapa de Fluxo e Permanência de Transeuntes da Rua Prudente de Moraes; Abaixo: Planta utilizada para Mapa de Fluxo e Permanência de usuários no Foyer da Sala Palma de Ouro; Ao lado: Legenda utilizada na identificação dos Fluxos e

Permanências.
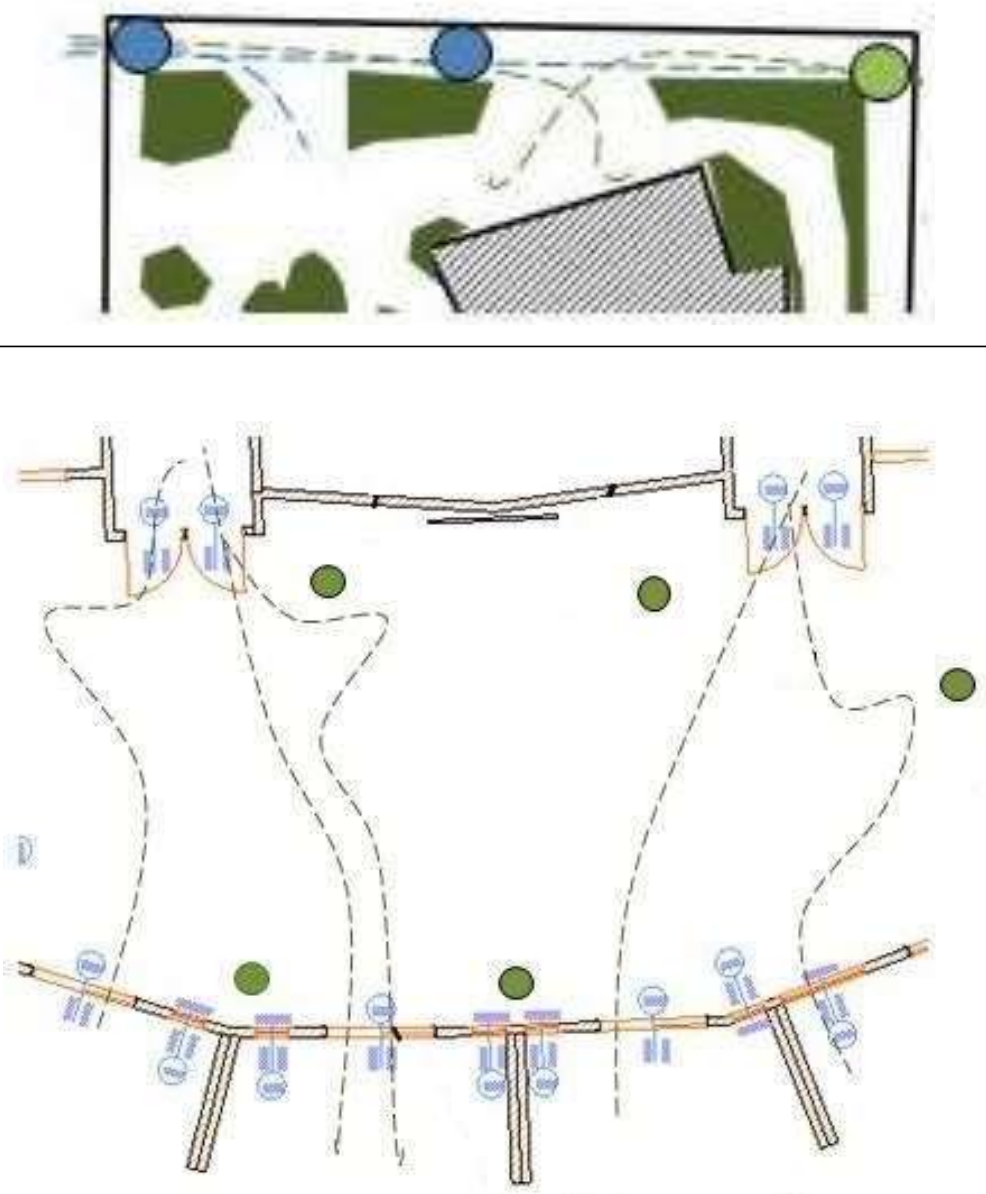

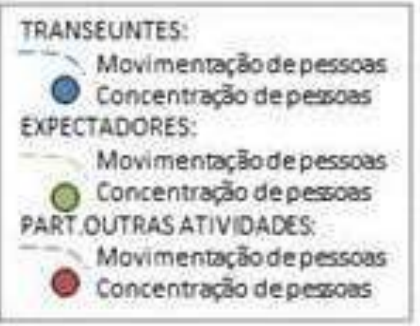

Foto: Mariana Baptista, 2017.

\section{CONCLUSÃO}

A aplicação da metodologia de Unwin (2013) foi bastante útil na identificação e setorização dos espaços para aplicação das Tabelas Analíticas e do Mapa de Fluxo e Permanência. A setorização dos ambientes internos e externos otimizou a aplicação das ferramentas de análise in loco, permitindo a leitura do espaço global por partes. Os elementos construtivos destacados pelo autor em seu livro "A análise da Arquitetura", são de rápida compreensão e identificação, fatores imprescindíveis para a análise prática dos ambientes construídos.

As Tabelas Analíticas foram fundamentais para que nenhum aspecto da Norma NBR 9050/2015 e do Desenho Universal deixasse de ser contemplado na análise, evitando que o Resultado Final apresentasse lacunas de pesquisa.

A aplicação do Mapa de Fluxo e Permanência foi importante para identificar como se dá a apropriação dos espaços pelos usuários. Aliado à setorização conseguida pela aplicação do método de Unwin (2013), o Mapa de Fluxo e Permanência foi capaz de identificar os aspectos mais sutis dos ambientes, como a apropriação de áreas sombreadas e as 


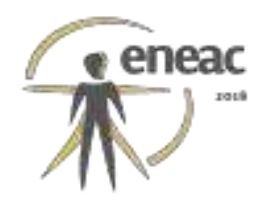

preferências de percurso em horários de eventos, além de apontar os trechos destacadamente mais acessíveis - a preferência dos transeuntes por "cortar caminho' pelo interior da quadra, fazendo uso de rampas mais suaves e espaços mais amplos sombreados, a caminhar pelos passeios públicos junto ao leito carroçável, percursos mais íngremes e estreitos, com menos sombreamento.

Esta pesquisa tem um desdobramento na elaboração de Mapas Temáticos como ferramenta de análise da Acessibilidade e do Desenho Universal, utilizando os Mapas de Fluxos e Permanências, validados através da pesquisa e passíveis de adaptação para o uso auxiliar no processo de projeto. O desenvolvimento destes Mapas Temáticos será objeto de outro artigo complementar (em elaboração) a este apresentado.

\section{REFERÊNCIAS}

AGUIAR, Fabíola de Oliveira; da SILVA, Antônio Nélson Rodrigues; RAMOS, Rui António Rodrigues; YUASSA, Vanessa Naomi. Avaliação de mobilidade em espaços urbanos com deficiências para pessoas com dificuldade de locomoção. $3^{\circ}$ Congresso Luso Brasileiro para 0 planejamento urbano, regional, integrado e sustentável. Santos: 2008.

COHEN, R.; Duarte, C.R. A percepção ambiental de pessoas com dificuldade de locomoção: uma contribuição para projetos acessíveis visando a inclusão psicossocial no ambiente construído. In: SEMINARIO INTERNACIONAL PSICOLOGIA E PROJETO DO AMBIENTE CONSTRUIDO, 2000, Rio de Janeiro. Interfaces e Possibilidades em Pesquisa e Aplicações. Rio de Janeiro: Luna, 2000. p.425-431.

\section{CONSTITUIÇÃO BRASILEIRA:}

http://www.planalto.gov.br/ccivil 03/constituicao/constituicao.htm, acessado em janeiro de 2016.

DECLARAÇÃO UNIVERSAL DOS DIREITOS DO HOMEM: https://nacoesunidas.org/ acessado em janeiro de 2016.

FEIJÓ, A.R.A. Direitos Humanos e Proteção Jurídica da Pessoa Portadora de Deficiência: Normas Constitucionais de Acesso e Efetivação da Cidadania à Luz da Constituição Federal de 1988. Brasília: Ministério da Justiça, Secretaria de Estado dos Direitos Humanos, 184 pp.

STORY, M.F. Principles of Universal Design. Universal Design Handbook, PREISER, W.F.E.; OSTROFF, E. (ed). New York: Mc-Graw-Hill, 2001.

RHEINGANTZ, P.A.; AZEVEDO, G.A.; BRASILEIRO, A.; ALCANTARA, D.; QUEIROZ, M. Observando a Qualidade o Lugar: Procedimentos para avaliação pós-ocupação. Rio de Janeiro: Universidade Federal do Rio de Janeiro, Faculdade de Arquitetura e Urbanismo, Pós-Graduação em Arquitetura, 2009. p. $35-42$.

UNWIN, Simon. A análise da arquitetura. Tradução técnica de Alexandre Salvaterra. 3 ed. Porto Alegre: Bookman, 2013. 